\title{
A Design of a Robust Analog PWM Solar Charge Controller for the Off-Grid Solar Home System: Fixed Frequency Current Control Mode
}

\author{
Mohammad Shariful Islam \\ Faculty of Electrical Engineering, IPSis, University Technology MARA (UiTM), 40450, Shah Alam, Selangor, Malaysia
}

Received May 2, 2021; Revised August 18, 2021; Accepted September 21, 2021

\section{Cite This Paper in the following Citation Styles}

(a): [1] Mohammad Shariful Islam , "A Design of a Robust Analog PWM Solar Charge Controller for the Off-Grid Solar Home System: Fixed Frequency Current Control Mode," Universal Journal of Electrical and Electronic Engineering, Vol. 8, No. 3, pp. 41 - 49, 2021. DOI: 10.13189/ujeee.2021.080301.

(b): Mohammad Shariful Islam (2021). A Design of a Robust Analog PWM Solar Charge Controller for the Off-Grid Solar Home System: Fixed Frequency Current Control Mode. Universal Journal of Electrical and Electronic Engineering, 8(3), 41 - 49. DOI: 10.13189/ujeee.2021.080301.

Copyright $\bigcirc 2021$ by authors, all rights reserved. Authors agree that this article remains permanently open access under the terms of the Creative Commons Attribution License 4.0 International License

\begin{abstract}
Solar Home System (SHS) is a stand-alone power solution in an isolated area where the national power grid connection is not accessible. Presently using the off-grid solar home system has one solar panel, one lead-acid batter, one PWM Solar charge controller, and $12 \mathrm{~V}$ DC power operated lamp solutions, fan, television, radio. Various solar home system packages have been introduced so far, which have offered different product features with price variations. Solar home system size is small, so producing energy is insufficient to fulfill the customer's demand. This research paper presented a novel feature analog PWM solar charging techniques through the algorithm of the fixed frequency current mode controller, which also satisfy the requirements of existing off-grid solar home system users to reduce self-power consumption thus purchasing at an affordable cost. This design set up four periods voltage threshold points as a safeguard for the battery to consider battery voltage level, cable length resistance, battery internal resistance, and EMI (Electromagnetic Interference) effects. PWM solar charging improves the charging strategy by protecting against surge voltage and lightning. The study is divided into three sections: solar charging, regulating signals, and voltage comparator. Accordingly, high-sophisticated fixed-frequency current mode controllers are a noise-free switching gate drive signal with simulation data. The design feature also ignores the EMI (Electromagnetic
\end{abstract}

Interference) noise impact on digital IC's input signals.

Keywords PWM, Self-Power Consumption, Surge Voltage, Efficient Charging, Fixed Frequency Current Control Mode

\section{Introduction}

The Charge Controller is a crucial instrument for the off-grid solar system and extending the life of the lead-acid battery. Solar charger, such as PWM solar charging device and MPPT (Maximum Power Point Tracker) solar charge controllers, are widely used for autonomous solar systems. The level of charge and discharge settings depend on the battery's power and scale: All are optimized for the extended battery life of the device. These devices have many features, such as LVD (low disconnection voltage level), HVD (disconnection high voltage level), LVR (reconnection low voltage load), HVR (reconnection low voltage load), etc. (reconnected high voltage charging). Because of device inadequacies, LVD (low voltage disconnection) and HVD (high voltage disconnection) protect the battery from deep discharge and extra charge. The cost of the solar charging controller depends on the charging devices' performance and efficiency. 


\section{Background of Study}

Sixty two percent of the regions primarily in the third-world countries, seem unable to supply power of conventional energy sources; to the affected rural areas. However, to enhance their living conditions, regular activities such as cooking, working, and teaching, the World Bank and the International Development Agency have launched an off-grid solar home system in that area. The living lifestyles are dramatically changed to incorporate the stand-alone solar home system (SHS). In [1] [2] [3], there was designed to concern over load projection and short circuit projection; these features are necessary for small scale solar system. Nevertheless, these designs lack lightning protection and self-power consumption reducing techniques.

\subsection{Off-Grid Solar System}

At the beginning of the solar home system for villagers, the manufacturer has introduced the solar home system in various packages in different sizes of the solar modules i.e $30 \mathrm{Wp}, 40 \mathrm{Wp}, 50 \mathrm{Wp}, 65 \mathrm{Wp}, 80 \mathrm{Wp}, 100 \mathrm{Wp} \& 120 \mathrm{Wp}$. These packages have consisted of some components which are solar panels, lead-acid battery, charge controlling device, and suitable load as per customers' requirements. From time to time, research has developed the features of the charge controlling devices and various DC-powered loads. According to the up-gradation of the solar home system of components concerning the different period, there has divided the three generations of the solar home system, as follow:

\section{A. FIRST-GENERATION SOLAR HOME SYSTEM}

At beginning of the announcing the solar home system solution, there has consisted of some components like a solar panel, lead-acid battery, solar charger, $12 \mathrm{~V}$ powered DC lamp, black \& white television, radio, etc. All components were linked with heavy sizing cables to connect the inter-connection and limited distance connected load. Initially, when the solar charge controller was used as a voltage regulator device, it has not maintained the charging efficiency. Solar charging systems and $12 \mathrm{~V}$ DC powered load was upgraded according to customer requirements as well as the new feature enhancement system had been launched.

\section{B. SECOND-GENERATION SOLAR HOME SYSTEM}

Advancement solar charge controlling device is obtainable with the use of the PWM solar charge controller, which is micro-controller-based. There has modernized the $12 \mathrm{~V}$ DC powered load with limited distance connected load cables such as mobile charger, solar lanterns (Portable LED Lamp), LED lamp, CFL lamp, etc. It has not maintained the necessary features of solar chargers that are self-power consumption, surge voltage protection, and lightning protection.

\section{THIRD GENERATION SOLAR HOME SYSTEM}

The most subsequent configured charge controller with an off-grid solar home system was implemented, which also has used PWM as well as MPPT techniques on even a microcontroller. To conquer the restricted cable barriers of distance for the specific situation, the DC to DC converter $(12 \mathrm{~V}$ to $48 \mathrm{~V})$ and $\mathrm{DC}$ to $\mathrm{AC}$ inverter $(12 \mathrm{~V} \mathrm{DC}$ to $220 \mathrm{~V} \mathrm{AC)}$ are being used to attach with standard domestic appliances including such LED lamp, LCD television, LED television, ceiling fan, CFL lamp, fluorescent lamp, stand fan, laptop or desktop power port, mobile phone charging power port, and many more. However, it has not maintained some vital features of the device such as self-power consumption, power conversion loss, surge voltage protection, and lightning protection.

Table 1 tabulates the comparison technical information of various solar home system package for the three generations.

The above discussion about existing solar home system components highlighted that the solar charge controlling devices, energy converter, and home appliances are being advanced to familiarize the new design techniques to fulfil the customer demands. Consequently, it has defined the design key factors of the solar charge controller and energy converter.

Table 1. Comparison table of solar home system packages

\begin{tabular}{|c|c|c|c|c|}
\hline NO & COMPONENTS & FIRST-GENERATION & SECOND GENERATION & THIRD GENERATION \\
\hline 1. & Solar panel & Monocrystalline/ Polycrystalline & $\begin{array}{c}\text { Monocrystalline/ } \\
\text { Polycrystalline }\end{array}$ & $\begin{array}{c}\text { Monocrystalline/ } \\
\text { Polycrystalline }\end{array}$ \\
\hline 2. & Battery & Lead Acid & Lead Acid & Lead Acid \\
\hline 3. & Type of solar charger & Voltage regulator & PWM Solar charger & PWM/MPPT \\
\hline 4. & $\begin{array}{c}\text { DC-AC inverter/DC to DC } \\
\text { Converter }\end{array}$ & It is not available & To fix as per requirement & $\begin{array}{c}\text { To use a standard mobile } \\
\text { charger }\end{array}$ \\
\hline 5. & $\begin{array}{c}\text { Customized mobile } \\
\text { charger }\end{array}$ & It is not available & Limited cable connection & Overcome this barrier \\
\hline 6. & $\begin{array}{c}\text { Limited distance cable } \\
\text { length }\end{array}$ & Limited cable connection & It is not available & Overcome this barrier \\
\hline 7. & Standard home appliance & It is not available & &
\end{tabular}




\section{Problems Statement}

\subsection{Self-Power Consumption for Solar Charger}

Solar self-consumption is the behavior of using solar energy to run equipment at home. The Solar Charger is connected to be aligned with the battery, the solar panel, and the loads to observe the charging and discharging of the battery for 24 hours. Therefore, it is vital to minimize the self-consumption of the solar charge controller because it has been connected to the system for 24 hours. In [2] [5] [7] [9] [19] and [20], the consumption of LED, LCD and IC impacts is more than $30 \mathrm{~mA}$. The nominal voltage of the battery is $12 \mathrm{~V}$, so the total energy consumption of the solar charge controller is -

$$
\begin{gathered}
\text { Total Energy Consumpation }=V X I X 24 \mathrm{Hrs} \\
=12 \mathrm{~V} X 0.03 \mathrm{~A} X 24 \mathrm{hrs} \\
=0.36 \mathrm{~W} X 24 \mathrm{hrs}=\mathbf{8 . 6 4} \mathbf{W a t t} / \mathbf{d a y}
\end{gathered}
$$

As a result, self-consumption is huge for a solar charger. The solar panel generates limited power and has major challenges in minimizing the self-consumption of the solar charge controller. However, even where spot trading is available, the primary way that most solar homes and businesses can save energy is being through self-consumption.

\subsection{Electromagnetic Interference (EMI)}

Micro-controllers are omnipresent. They have been used in vehicles, mobile phones, appliances, and many wireless devices. Lots of micro-controllers can be found in the electrical networks of a commercial vehicle in systems such as cars. The power supply conductors of these micro-controllers are also applied to multiple electromagnetic interferences from generators, alternators, and motors. Noise is attributable to electromagnetic interference from external sources at frequency bands attained that induce from the conductors of a power supply.

Switch Mode Power Supplies (SMPS) occur due to rapidly changing voltage and current for them from conducted and radiated EMI concerns. This enables surrounding devices and input power lines to interrupt because of DC-DC power converters. Integrated circuits frequently play a significant role in electromagnetic consistency (EMC) of an electronics system, which ultimately impacts the micro-controller because of making noise and unexpected signal to occur malfunction, reducing EMI is also a very important problem.

\section{Aim and Objectives}

The objectives of this research project are to design a new robust analog PWM solar charge controller for the off-grid solar home system through the algorithm of fixed frequency current controlling mode to disregard the EMI noise effect. Designed addressing are two features one of which is reducing the self-power consumption techniques and the other is surge voltage \& lightning protection techniques.

\section{Research Methodology}

\subsection{Problems Formulation for the Solar Charger}

It is essential to consider the various algorithm of solar charging circuits. In this phase, there have been problems with formulating for PWM solar charger as per referring to the objectives. It is necessary to develop some design topologies concerning research goals. The following are the methodology for PWM solar charger:

\subsubsection{Pulse Width Modulation (PWM) Method}

There are two functions for digital signals. It is defined as on or off or, for short 1 or 0 . On the other side, analog symbols will hit 1 or drop off, two-thirds of the way to on, and infinite positions from 0 to 1 . The method can control the analog signal by using digital output. PWM is a means of tracking analog signals to generate a digital output. The PWM constant frequency signal can be obtained by comparing the ramp or carrier signal with the error between the desired output voltage signal and the true output voltage signal. In other words, a modulated signal may be transmitted to an analog signal from a digital signal (i.e. Microcontroller Unit).

\subsubsection{Fixed Frequency Current Control Mode}

The Fixed Frequency Current Mode algorithm has become a dynamic self-supply mechanism that significantly simplifies the configuration of the auxiliary supply and $V_{\text {cc }}$ capacitor by enabling internal startups, transients, latch standby, etc. Dynamic self-supply is useful to keep the controller alive although no switching pulses are provided, e.g. in blown-out conditions, or to prevent the formation of the controller from stopping during a transient load when $\mathrm{V}_{\mathrm{cc}}$ can drop. It contains a timer-based fault detection that maintains overload identification, with dynamic compensation, to assist keep the maximum power independently of the input voltage.

\subsection{Development of Solar Charger Algorithm}

The statement of the problem which establishes the algorithm of fixed frequency current mode controller to achieve desired objectives are being evaluated. The appropriate software should also be selected for the designing and simulation of the schematic diagram.

\subsubsection{Designing Analog PWM Topology}

A triangle wave generator and comparator with a duty 
cycle to produce a PWM waveform that is inversely proportional to the input voltage. The operating amplifier and comparator create a triangular waveform which is transmitted to the inverting input of the second comparator. The PWM waveform negative feedback to the error amplifier is used to ensure high accuracy and linearity of the signal. The output of the triangle wave generator circuit is being checked to ensure that it met the intended specifications. These values should be appropriately similar to the design values for the overall device output to conform to design parameters.

\subsubsection{Designing the Voltage Comparator}

A voltage comparator is compared with the voltage with two input voltages. The Op-amp voltage comparator is simple to design that threshold stress and width of the hysteresis are expressed. Operational amplifiers built as amplifiers are not particularly suitable as comparators, especially in applications like audio level sensors or digital transformations as input signals rapidly alter. Figure 1 shows the voltage comparator designing block diagram-

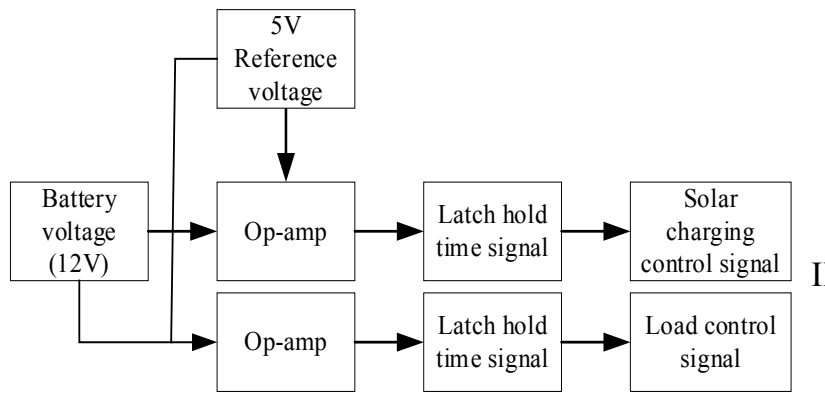

Figure 1. The block diagram of the voltage comparator

\subsubsection{Designing Gate Drive Charge Pump}

Some implementations demand that the output voltage control be retained while the applied voltage is just marginally some sophisticated than the output voltage. For a buck converter, such poor headroom conditions require a high duty cycle signal of up to $100 \%$. The charge on the boot condenser must be held to retain the high-side transition and hence to maintain the loop as the turn-around time converter reaches the switching. Figure: 2 , shows the N-MOSFET gate drive charge pump designing circuit-

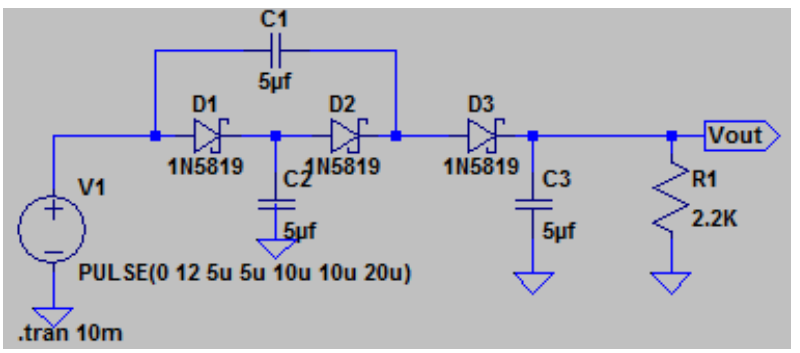

Figure 2. N-MOSFET gate drive charge pump

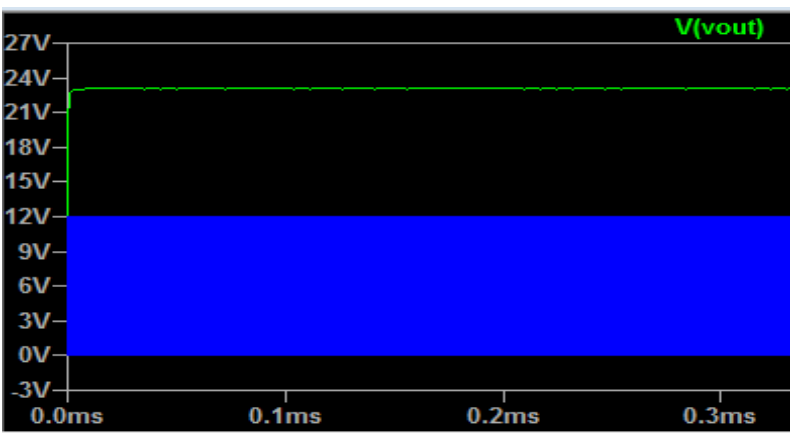

Figure 3. Waveform of N-MOSFET gate drive signal

\subsubsection{METHOD FOR REDUCING THE SELF-POWER CONSUMPTION}

Two techniques have been implemented two for reducing self-power consumption: Detailed descriptions of techniques are as follows:

I. The dedicated off program allows the fixed-frequency current control mode to achieve exceptionally low no-load input power consumption through the "sleeping" of the entire system, thus reducing the power consumption of the control circuitry. Based on the frequency fold-back, the controller has outstanding efficiency in light load conditions whilst also maintaining very low stationary power usage. Specific frequency, ramp compensation, and versatile latch feedback enable the controller an outstanding output for the desired design.

II. This same solar charge has been using LCD and LED to obtain appropriate status, the whole arrangement identity wants and needs to make a distinction two or three times each day, a certain duration seems to be roughly 30 seconds. Nevertheless, that is really the power feasting besides 24 hours, and therefore it is one source of power consumption. The push switch circuit technique, which would constitute an Op-amp and an NPN transistor, is willing to take responsibility for with this dedication. Figure 4, shows the block diagram of push switch mechanism:

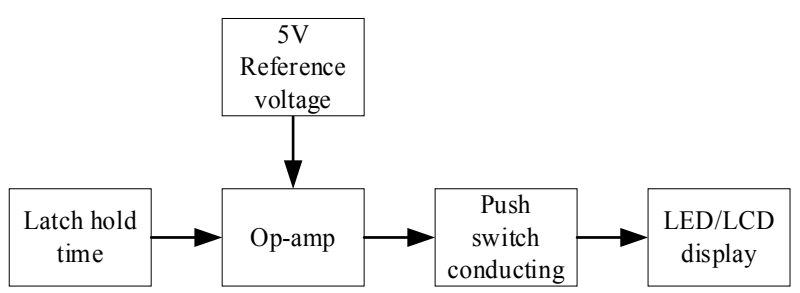

Figure 4. Block diagram of push switch techniques

\section{Designing, Simulation \& Analysis}

Analog pulse width modulation (PWM) comparator that has eight characteristics including current limit control or sinks peak current, feedback voltage loop for stability, adding slope compensation, oscillation timing 
for fixed-frequency operation, signal \& power returning ground, PWM drive signal for N-MOSFET which is shown in Figure: 6, Clamp voltage source and voltage reference for error amplifier. Oscillation timing is fixed to use the timing resistor (RT) and timing capacitor, RT resistor is connected to reference voltage and CT capacitor is connected to ground. RT/CT values define the fixed frequency oscillation timing, that frequency defines the following formula-

$$
\mathrm{f}_{\mathrm{ocs}}=\frac{1.72}{R_{R T} \times C_{C T}}=\frac{1.72}{12 \mathrm{~K} X 220 \mathrm{P}}=651.5 \mathrm{kHz}
$$

Timing resistor values should be greater than $5 \mathrm{~K} \Omega$ and timing capacitor values between $1 \mathrm{nF}$ to $100 \mathrm{nF}$ for the fixed frequency algorithm, which waveform is shown in Figure 7 \& Figure 8 . The total supply current depends on the output current and its quiescent current is $0.5 \mathrm{~mA}$. It depends on the input voltage and loading condition, that function is the continuous conducting method (CCM) or discontinuous conducting method (DCM). PWM controller output can be shut down to sink the current or can be command zero duty cycle by applied the external voltage at the compensation of PWM controller. Feedback voltage $\left(V_{F B}\right)$ should be less than 1.5 Volt for system stability that voltage gets from inverting input of the error amplifier. The MOSFET source terminal has come in contact with the sense resistor to incorporate slope compensation of a voltage ramp across Current sense ( $\mathrm{I}_{\text {SENSE }}$ ) point, that $\mathrm{R}_{\text {SENSE }}$ resistor value is less than $0.05 \Omega, V_{\text {SENSE }}$ voltage is 1 volt; that peak $I_{\text {SENSE }}$ defines the following formula -

$$
\mathrm{I}_{\text {SENSE }}=\frac{\mathrm{V}_{\text {SENSE }}}{\mathrm{R}_{\text {SENSE }}}=\frac{1}{0.05}=20 \mathrm{~A}
$$

The significance of the $R_{\text {SENSE }}$ resistor, which is across the voltage, involves determining the short circuit protection current as well as the overload protection current. The $\mathrm{I}_{\text {SENSE }}$ signal is the noninverting signal, which is compared with error gain voltage, and aims to ensure the reliable operation of the device. High impedance supply rail concerning the ground, that effect is an obstacle for noise-free PWM signal. Because the snubber circuit is used at the output terminal of the PWM driver, one PNP transistor and one NPN transistor are used as a snubber circuit, that is ensured the noise-free N-MOSFET drive gate PWM signal. MOV (Metal Oxide Varistor) is used to the solar panel port in series connection to prevent the surge voltage due to the impact of lightning. Figure 5, shows the block diagram of PWM charging-

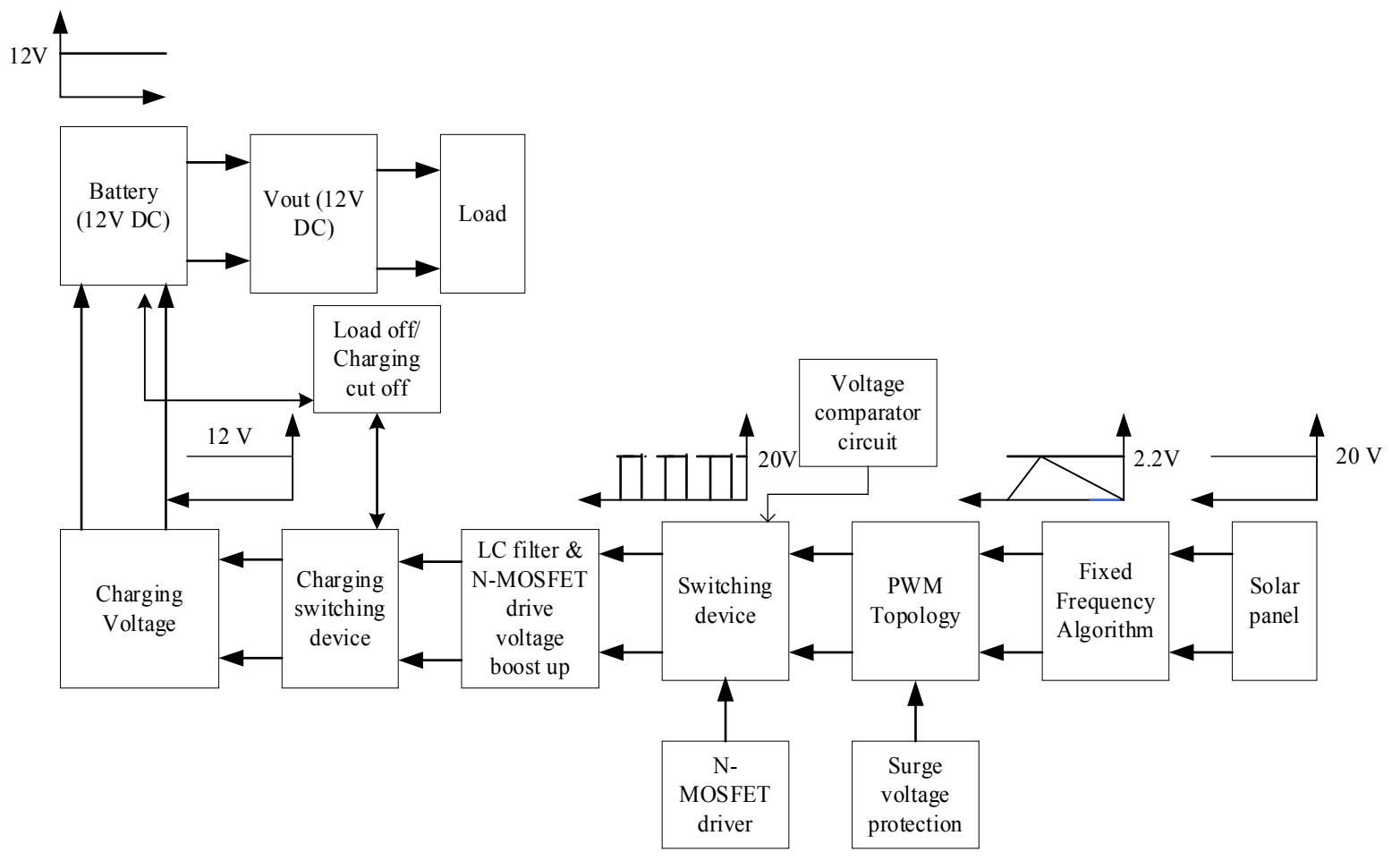

Figure 5. Block diagram of PWM charging technique 


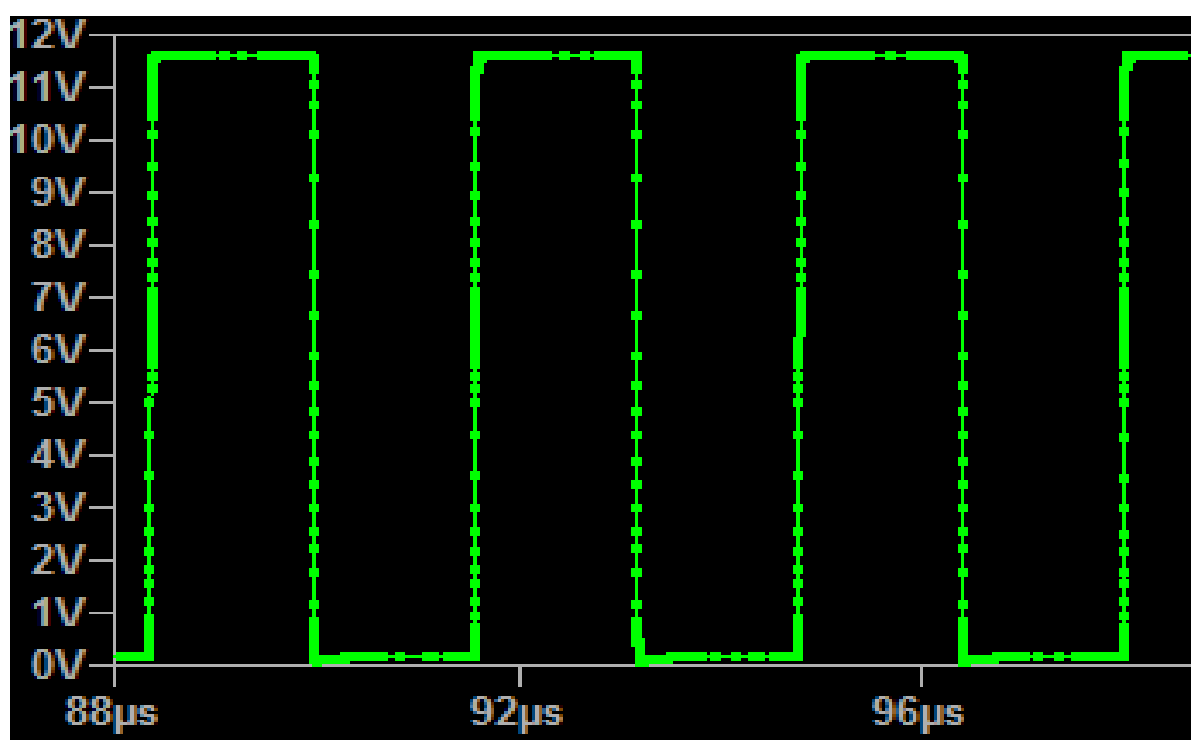

Figure 6. PWM drive signal for N-MOSFET

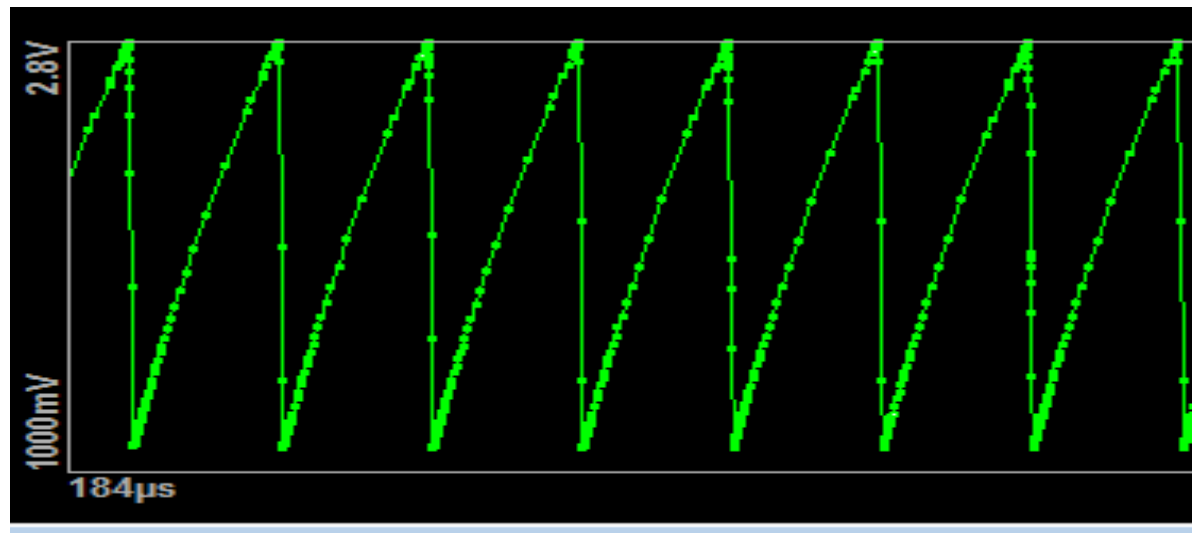

Figure 7. Waveform of voltage ramp

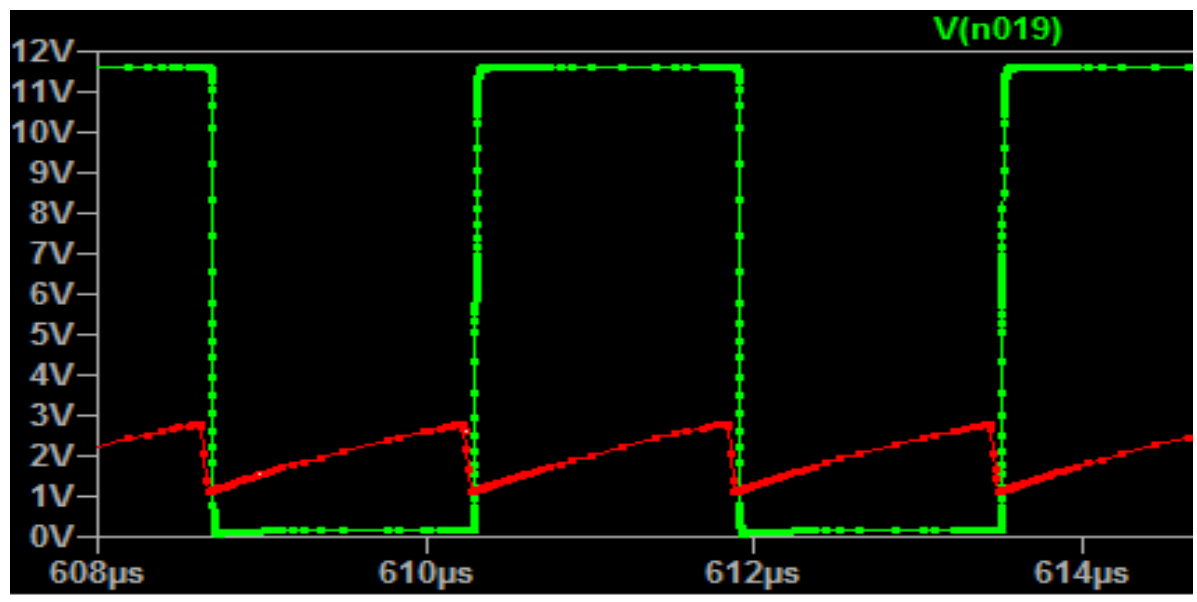

Figure 8. Waveform of voltage ramp and PWM output

Sawtooth wave (voltage) depends on the value of the timing resistor (RT) and the value of the timing capacitor (CT). Here, the red waveform is a sawtooth wave and the green waveform is the PWM switching signal that is followed by the sawtooth wave. Noise-free gate drive signal depends on $\mathrm{V}_{\mathrm{CC}}$ voltage that is coupled with $\mathrm{V}_{\mathrm{IN}}$ capacitor $(\mathrm{C} 7=$ $2200 \mu \mathrm{F}$ ) because of high impedance supply rail concerning ground. 
Table 2. show the simulated result according to the various condition of battery voltage level-

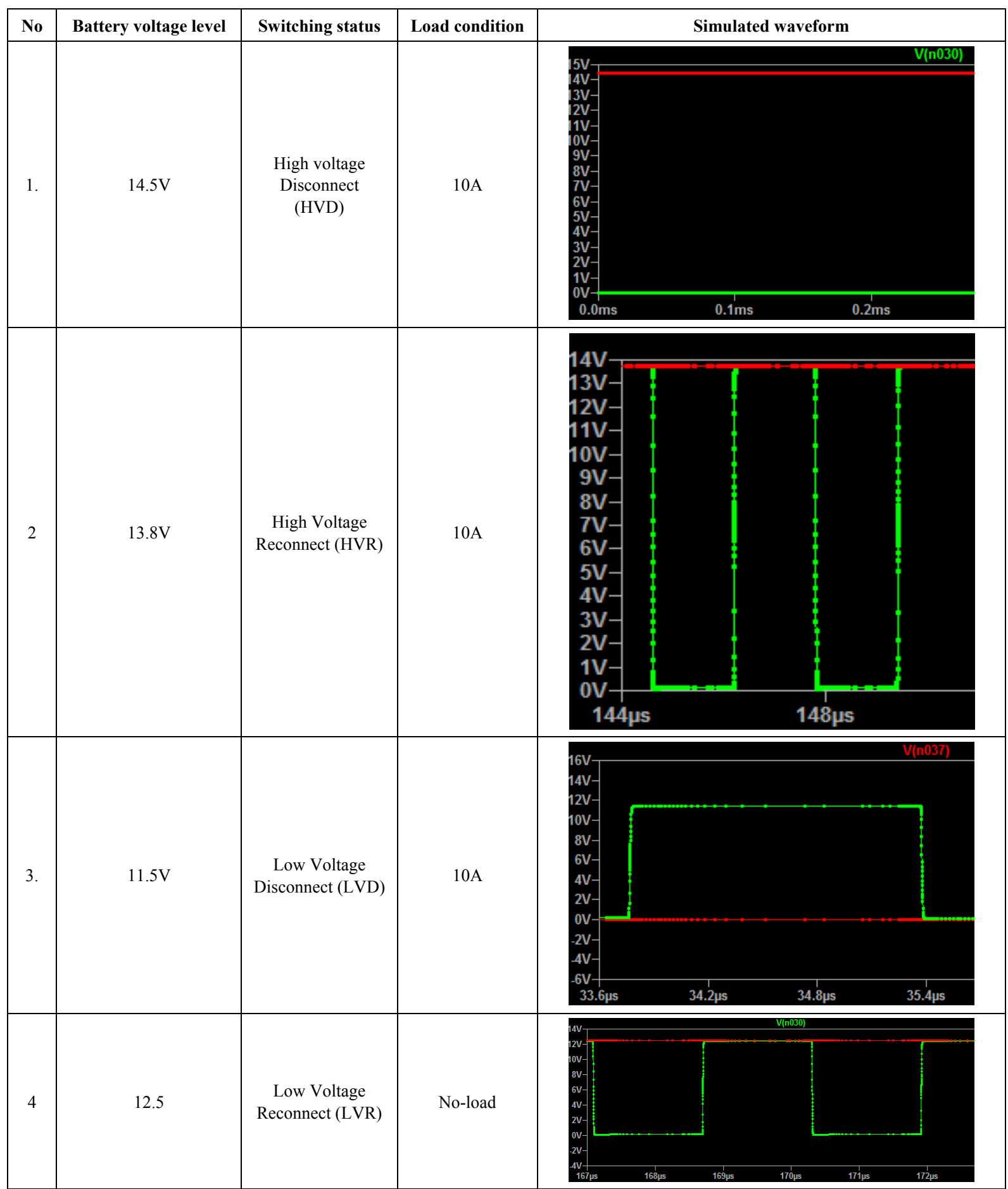

Where Green color: solar charging PWM waveform and red color: switching waveform according to the battery voltage level.

The operational amplifier sets the various switching thresholds of voltage according to the different voltage conditions of the battery. It has two major switching parts. One is solar charging with battery and the other is a load connected with the battery. The hysteresis voltage difference is $0.7 \mathrm{~V}$ between the solar charging disconnect point and reconnected point. The hysteresis voltage difference is $1 \mathrm{~V}$ between the load disconnect point and reconnect point. Hysteresis threshold values are set through the PNP transistor and resistor voltage dividing programming. Table 3 , describes the switching orientation throughout relation to the different battery operating voltage that have been discussed in order to describe shown above wave pattern 
Table 3. Switching alignment as per battery voltage level

\begin{tabular}{|c|c|c|c|l|}
\hline No & Battery voltage & Load condition & Switching status & \multicolumn{1}{c|}{ Functional status } \\
\hline 1 & $14.5 \mathrm{~V}$ & $10 \mathrm{~A}$ & $\begin{array}{c}\text { High Voltage Disconnect } \\
\text { (HVD) }\end{array}$ & $\begin{array}{l}\text { Solar charging is disconnected } \\
\text { Load connected } \\
\text { Battery full charged }\end{array}$ \\
\hline 2 & $13.8 \mathrm{~V}$ & $10 \mathrm{~A}$ & $\begin{array}{c}\text { High Voltage Reconnect } \\
\text { (HVR) }\end{array}$ & $\begin{array}{l}\text { Solar charging is reconnected } \\
\text { Load connected } \\
\text { Battery status is healthy }\end{array}$ \\
\hline 3 & $11.5 \mathrm{~V}$ & $10 \mathrm{~A}$ & $\begin{array}{c}\text { Low Voltage Disconnect } \\
\text { (LVD) }\end{array}$ & $\begin{array}{l}\text { Solar charging is connected } \\
\text { Load disconnected } \\
\text { Battery status is deep discharged }\end{array}$ \\
\hline 4 & $12.5 \mathrm{~V}$ & No-load & $\begin{array}{c}\text { Low Voltage Reconnect } \\
\text { (LVR) }\end{array}$ & $\begin{array}{l}\text { Solar charging is connected } \\
\text { Load reconnected } \\
\text { Battery status is fit for discharge }\end{array}$ \\
\hline
\end{tabular}

\section{Conclusion}

The academic research these have demonstrated the configuration of analog PWM solar charge controller, that incorporates several functionalities including such surge voltage protection, short circuit as well as overload protection, and minimizing self-power consumption to acclimate the methodology with push switch and fixed frequency technique. These research works have two novelties. One is lighting projection features for a small-scale solar home system and the other is reding the self-power consumption. The operational amplifier is setting the various threshold voltage to omit micro-controller because of micro-controller is occurred malfunction. There is no need for the shield protection to protect from EMI noise. The overall testing techniques are followed according to the battery voltage under the various load conditions including all parameters.

\section{REFERENCES}

[1] Vaz, A. C., Gurudas Nayak, C., \& Nayak, D. Pulse Width Modulation based Solar Charge Controller. Proceedings of the 3rd International Conference on Electronics and Communication and Aerospace Technology, ICECA 2019, 1067-1071. https://doi.org/10.1109/ICECA.2019.8822050

[2] Das, S., Thotakanama, N. K., \& Manickavasagam, K. Analysis and design of fuzzy-based PWM controller for solar power generation. Proceedings of 2017 IEEE International Conference on Technological Advancements in Power and Energy: Exploring Energy Solutions for an Intelligent Power Grid, TAP Energy 2017, 1-6. https://doi.org/10.1109/TAPENERGY.2017.8397263

[3] Vaz, A. C., Gurudas Nayak, C., \& Nayak, D. Pulse Width Modulation based Solar Charge Controller. Proceedings of the 3rd International Conference on Electronics and Communication and Aerospace Technology, ICECA 2019, 1067-1071. https://doi.org/10.1109/ICECA.2019.8822050

[4] Wing Wira, A. R., Rezky, A., Bastian, A., Devara, K., Udhiarto, A., \& Abuzairi, T. Development of simple solar charge controller using 8-bit microcontroller attiny85. E3S
Web of $\quad$ Conferences, 67.
https://doi.org/10.1051/e3sconf/20186701018

(2018).

[5] Belattar, A., El Hamdaouy, A., \& Madi, A. A. Multi-criteria and hierarchical level energy management system for light solar vehicle integrating a supercapacitor. Journal Europeen Des Systemes Automatises, 53(3), 317-326. (2020), https://doi.org/10.18280/jesa.530302

[6] Yildirim, I. K., \& Baysal, U. Comparison of MPPT and PWM methods on designing microcontroller-based power control unit for wireless sensor networks. Proceedings 2019 6th International Conference on Electrical and Electronics Engineering, ICEEE 2019, 263-268. https://doi.org/10.1109/ICEEE2019.2019.00057

[7] Mohammed, S. A., \& Hashim, E. T. Designing a maximum power point tracking system for a monocrystalline silicon solar module using the Arduino microcontroller and synchronous Buck converter. FME Transactions, 47(3), 524-533. (2019), https://doi.org/10.5937/fmet1903524M

[8] Sofijan, A., Nawawi, Z., Suprapto, B. Y., Sipahutar, R., \& Bizzy, I. Performance Evaluation Solar Charge Controller on Solar Power System Home-Based SPV Amorphous 80 Watt-peak. Journal of Physics: Conference Series, 1500(1). (2020), https://doi.org/10.1088/1742-6596/1500/1/012004

[9] Bavchakar, A., Chougale, P. K. N., Belanekar, S. S., Rane, S. P., \& Sawant, N. B. A Hybrid Model of Vertical Axis Wind Turbine-Solar Power Generation for Highway and Domestic Application. 7th IEEE International Conference on Computation of Power, Energy, Information and Communication, ICCPEIC 2018, 135-139. https://doi.org/10.1109/ICCPEIC.2018.8525152

[10] Chaudhari, M., Babu, K., Khubalkar, S. W., \& Talokar, S. Off-Grid Hybrid Online Solar Power Conditioning Unit for Domestic Purposes. 2019 International Conference on Computing, Power and Communication Technologies, GUCON 2019, 121-126.

[11] Situmorang, M., Brahmana, K., \& Tamba, T. Solar Charge Controller Using Maximum Power Point Tracking Technique. Journal of Physics: Conference Series, 1230(1). (2019), https://doi.org/10.1088/1742-6596/1230/1/012090

[12] Baliwant, B. B., Gothane, A. R., \& Waghmare, V. B. PWM based charge controller for renewable energy applications using sepic converter. Proceedings of the 3rd International Conference on Computing Methodologies and Communication, ICCMC 2019, 1051-1054. 
https://doi.org/10.1109/ICCMC.2019.8819755

[13] Abuzairi, T., Ramadhan, W. W. A., \& Devara, K. Solar Charge Controller with Maximum Power Point Tracking for Low-Power Solar Applications. International Journal of Photoenergy, 2019. https://doi.org/10.1155/2019/5026464

[14] Megantoro, P., Prabowo, I. E., \& Shomad, M. A. Development of Maximum Power Point Tracking Solar Charge Controller for 120 Volt Battery System at Pandansimo Hybrid Power Plant. Journal of Physics: Conference Series, 2020, 1471(1). https://doi.org/10.1088/ $1742-6596 / 1471 / 1 / 012047$

[15] Abdelilah, B., Mouna, A., M'Sirdi, N. K., \& Hossain, A. El. Solar charge controller with a data acquisition system based on arduino. Lecture Notes in Electrical Engineering, 2019, 519, 412-420. https://doi.org/10.1007/978-981-13-1405-6 $-49$

[16] Rokonuzzaman, M., \& Hossam-E-Haider, M. Design and implementation of maximum power point tracking solar charge controller. 2016 3rd International Conference on Electrical Engineering and Information and Communication Technology, ICEEiCT 2016. https://doi.or $\mathrm{g} / 10.1109 / \mathrm{CEEICT} .2016 .7873139$

[17] Xie, S., \& Jin, F. Low power consumption solar PV Charge Controller for telemetry system. Proceedings of 2016 IEEE Advanced Information Management, Communicates, Electronic and Automation Control Conference, IMCEC 2016, 1132-1136. https://doi.org/10.1109/IMCEC.2016.78 67388

[18] Acharya, P. S., \& Aithal, P. S. A Comparative Study of
MPPT and PWM Solar Charge Controllers and their Integrated System. Journal of Physics: Conference Series, 2020, 1712(1). https://doi.org/10.1088/1742-6596/1712/1/ 012023

[19] Pagatpatan, G. I., Pagkaliwangan, J. P., Torcuato, D. K. A., Virrey, G. C., Ramos, J. P. M., \& Valenzuela, I. C. Neuro-fuzzy based MPPT for solar PV panel. International Journal of Emerging Trends in Engineering Research, 8(8). (2020) https://doi.org/10.30534/ijeter/2020/108882020

[20] Kuder, K. M., Hussein, H. A., \& Numan, A. H. Solar Photovoltaic Direct-Driven Air Conditioning System Performance in Iraq. Engineering and Technology Journal, 38(7A). 2020. https://doi.org/10.30684/etj.v38i7a.477.

[21] Chaudhari, M., Babu, K., Khubalkar, S. W., \& Daigavane, P. Off-grid hybrid solar power conditioning unit for critical and non-critical loads. 2019 International Conference on Intelligent Computing and Control Systems, ICCS 2019, 969-974.

https://doi.org/10.1109/ICCS45141.2019.9065782

[22] Sepulveda Mora, S. B., Luna Paipa, E. A., Laguado Serrano, M. A., \& Bustos Márquez, L. F. Performance comparison between PWM and MPPT charge controllers. Scientia et Technica, 24(1). (2019). https://doi.org/10.22517/2344721 4.20681

[23] Madububa, B. I., Mbagwu, J. C., \& Isiohia, D. O. Design, Construction, and Testing of Maximum Power Point Tracking (MPPT) Charge Controller for Photovoltaic (PV) Power Generation. Journal of Engineering Research and Reports, 36-47. 2020. https://doi.org/10.9734/jerr/ 